\title{
Effect of Stakeholders' Awareness of Vision and Mission Statements on Internal Efficiency in Public Secondary Schools: The case of Kisumu and Usain -Gishu Counties, Kenya
}

\author{
Ezekiel Nyangia ONYANGO ${ }^{1}$ John Aluko ORODHO*2 JohnNDERITU ${ }^{3}$ \\ 1.Doctor of Philosophy (PhD) Student, School of Education, Department of Educational Management, Policy \\ and Curriculum Studies, Kenyatta University, Kenya \\ 2.Associate Professor, School of Education, Department of Educational Management, Policy and Curriculum \\ Studies, Kenyatta University, Kenya \\ 3.Lecturer, Department of Educational Management, Policy and Curriculum Studies, School of Education, \\ Kenya
}

\begin{abstract}
The study sought to establish the effect of stakeholders' awareness of vision and mission statements on internal efficiency in terms of promotion rates and retention. The convergent parallel mixed-methods design was employed in the study. A sample size of 342 comprising 57 principals, 57 PA chairpersons; and 228 teachers in the quantitative phase and a further 54 respondents comprising 9 principals, 9 PA chairpersons and 36 teachers for qualitative strand. Data were collected via Questionnaires, interview schedule, document analysis and observation schedules. The study found that all stakeholders were aware of the school vision and mission statements, although the principals were more aware than the rest. The overall awareness was moderate and had a positive influence on internal efficiency in terms of grade promotion rate than on retention. It was concluded that stakeholders' awareness of vision and mission statements has positive moderate influence on internal efficiency in public secondary schools. The study recommends that The Ministry of Education consistently sensitize key stakeholders on school vision and mission statements.
\end{abstract}

Keywords: Stakeholders' Awareness, Vision and Mission Statements, Internal Efficiency, public secondary schools, Kenya.

DOI: $10.7176 / \mathrm{JEP} / 11-26-01$

Publication date:September $30^{\text {th }} 2020$

\section{Introduction}

Education is a prerequisite for human development, and it is critical in diverse economic growth. It is not only a fundamental human and enabling right, but also a public good (UNESCO, 2015). It remains the unlocking key to the individual's intellectual and creative prowess and by investing in expanding access to quality education, majority of societies have achieved high and sustained rates of growth or considerable poverty alleviation among other benefits (Khamati \& Nyongesa, 2013, Republic of Kenya, 2010, 2013).

Internationally, the importance of educational development and the fact that secondary education is to equip learners with knowledge, skills and values to not only compete in securing quality courses and colleges but also to be absorbed in the world of work have led to many countries investing in the provision of Free Secondary Education (UNESCO, 2000, 2015). For instance, countries like Britain, US, Sweden, Egypt and Canada, among others, started in the 1950 s to finance secondary education, an undertaking that could have partly contributed to the advancement of these nations (Khamati \& Nyongesa, 2013).

A number of studies conducted in Nigeria, Uganda and Kenya among other African countries purport that they are implementing this reality of Free Secondary Education (FSE) with only a few nations levying lower secondary school fees and those that have abolished fees have expanded access to secondary school education with increased enrolments (UNESCO, 2015). There had been need for a form of approach, which could enhance efficiency through judicious and efficient utilization of educational resources provided through enormous sacrifices by educational partners (Republic of Kenya, 2012).

The governments globally including Kenyan, have attempted to adopt many approaches of planning such as social demand, work force, cost benefit analysis and strategic planning. The first three approaches of planning have been inadequate in addressing the demands of the dynamic environment in which education is conducted. They are bedeviled by this limitation due to their static and crisis driven nature and lack of provisions for a framework, which strategic planning approach provides, to meet the needs in educational arena. Research has confirmed that Strategic planning is one of the major steps that organisations such as schools can take to mitigate the challenges, for instance inefficiency, confronting them as they endeavor to provide quality of their programmes in education. Strategic planning has, therefore, been adopted in learning institutions as a means of achieving school efficiency (Kiprop, Bomett \& Michael, 2015). It was on this premise that the Ministry of Education through Sessional Paper No 1 of 2005 mandated all school managers in Kenya to develop strategic plans for better 
management of their institutions (MoEST, 2005). It was also on the same basis that the current study focused on strategic planning and not the other approaches of planning.

Strategic planning was first introduced in the institutions of learning to address quality of education and efficiency in utilization of meager educational resources. Steyn and Wolhuter (2010) confirm that strategic planning has been identified as not only a valuable framework for successful implementation of school reforms but also empowers schools to effectively respond to their needs such as improvement of their internal efficiency. For instance in Kenya, $6.4 \%$ share of the Gross Domestic Product (GDP) goes towards education which meets the international benchmark (Republic of Kenya, 2014) and $58 \%$ of this is used to finance secondary education (Republic of Kenya, 2014, 2015).

These are nation's scarce resources, which must be utilized under the guidance of strategic planning in enhancing internal efficiency by reducing students' dropout and grade repetition in secondary education without disadvantaging any deserving student, especially those from low-income households. With such resources, literature confirms that strategic planning can see wastage rate reduced to minimum by ensuring that facilities in the institutions are improved on to accommodate more students (Abdulkhareem, Akinub \& Oyenivan, 2014), especially at this time when the government is implementing $100 \%$ transition from primary to secondary levels of education. However, this can only be possible if the implementation of the plan is guided by the stakeholders' awareness of vision and mission statements.

In 2012, the Government of Kenya through the Ministry of Education in partnership with USAID initiated the Decentralized Education Management Activity (DEMA) to embark on capacity development among education managers at district and at school levels to enable them prepare and implement strategic plans ( Itegi, 2016). The capacity-building workshop by DEMA was carried out in all the counties. For the Republic of Kenya (2013) therefore, the process of restructuring the Ministry of Education, Science and Technology (MoEST) and the need to respond to the demands of the Constitution of Kenya 2010, and the vision 2030 necessitated the development of The MoEST Strategic Plan for the period 2013-2018.

When schools implement strategic plans, there are certain indicators, which will be evident. The key stakeholders must be aware of the vision and mission statements, for instance. This enables them to work as a team towards the same direction in ensuring that strategic objectives of the institution are achieved. The position is implied by a study by Chemwei, Leboo and Koech (2014) on factors that impede the implementation of strategic plans in secondary schools in Baringo District, Kenya, which established that unclear vision and mission to implementers constrain implementation of strategic plan. Implementation is what makes strategic planning unique. The current study, therefore was seeking to establish whether with the display of vision and mission statements on the walls of schools' gates, key stakeholders were aware of them and what was the effect of this awareness?

The expectation of the government from 2013, therefore, is that public schools should improve in their performance generally in the five areas identified by IIEP (2010) with implementation of strategic plan. These are access; internal and external efficiencies, quality and equity. Despite the mandate and significant progress in terms of reforms and expenditure since 2000, there has been growing concern on educational performance, especially, internal efficiency that requires policy attention (MoEST, 2010).

Kisumu and Uasin Gisu Counties' QASOs noted that critical issues affecting education rigid students grade to grade promotion policies by schools fighting for better mean scores, lack of teaching and learning resources within schools due to insufficient government and public funding, lack of school physical facilities like science laboratories, classroom and latrines among others. Such conditions could only be improved if all the stakeholders have a resolve influenced by their awareness of vision and mission statements.

The indicators of internal efficiency are repetition, retention, promotion and dropout rates, percentage of repeaters' school life expectancy, survival rates by grade, coefficient of efficiency, year-input per graduate amongst others (IIEP, 2010). This study was concerned with retention and grade promotion of students, which entail interrogating students' repetition and dropout since they had been seriously affected, by the condition of resources in public secondary schools in Kisumu and Uasin Gishu Counties (MoEST, 2014). These are conditions which strategic plan implementation is supposed to improve as guided by the stakeholders' awareness of vision and mission statements. Another reason is that computation of indicators of internal efficiency requires large amount of data, therefore, due to limitation of time and finance the current study was not able to accomplish the required computation. Secondary schools in Kenya still exhibited some elements of low internal efficiency in the school system (MoEST, 2014) showing a gap between the actual and the expected outputs which was a repeat of MoEST (2007) report. View of national retention and dropout rates is portrayed as a trend from 2009 to 2017 as shown in Figure 1. 


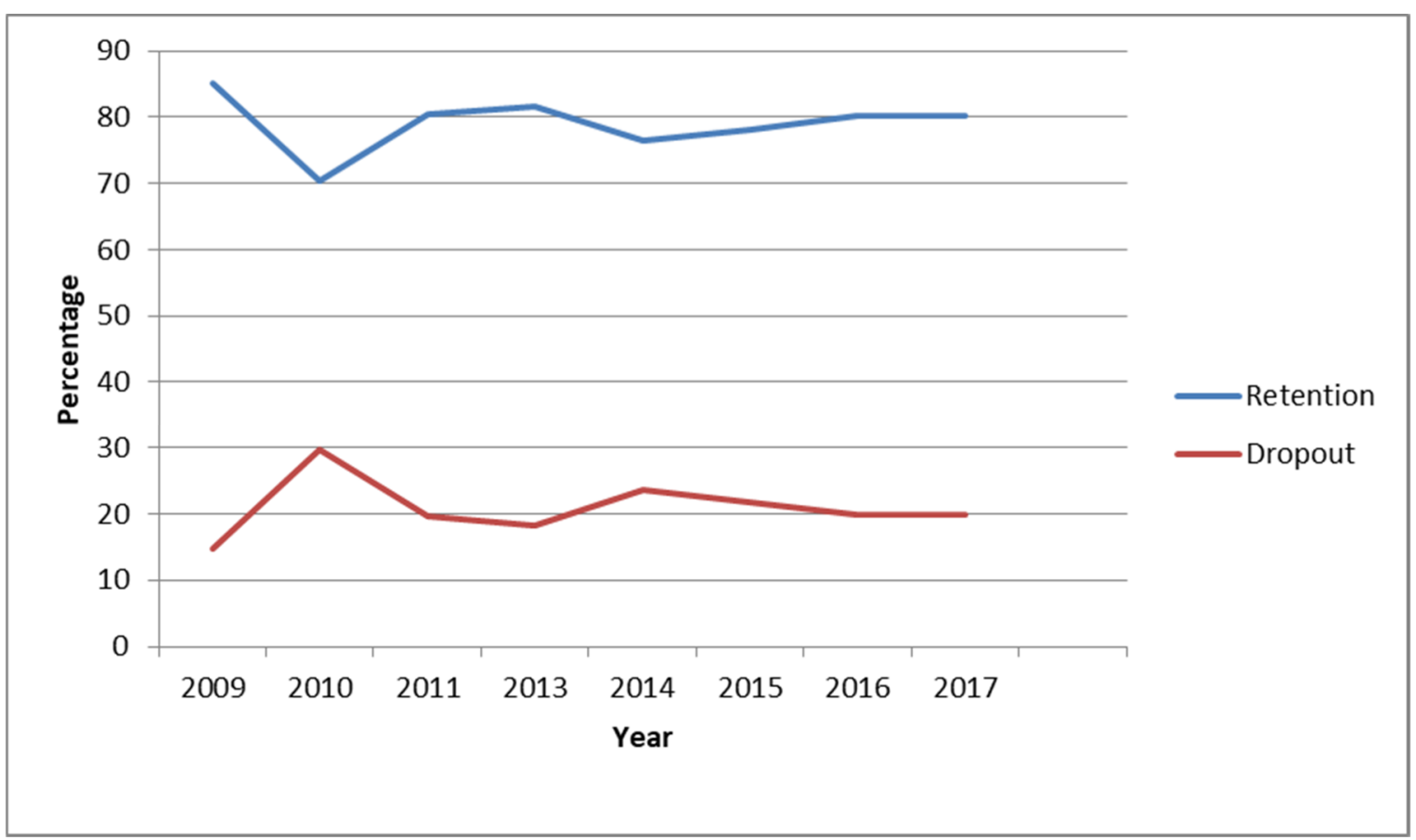

Figure 1: National retention and dropout rates for secondary schools for years 2009-2017

Source: Ministry of Education 2018

From Figure 1, retention rates in secondary from Form 1 to Form 4 in: 2009 is $85.2 \%$; 2010 was $70.35 \%$; 2011 was $80.4 \%$; 2012 was $86.9 \%$; 2013 was $81.7 \%$ and 2014 with a sharp drop to $76.4 \%$. Then it moved to $78.2 \%$ in 2015 and then $80.3 \%$ for 2016 and 2017. The report showed a fluctuating trend without giving any reason (MoEST, 2018). The interpretation of this report was that the difference between the enrolment percentage rate $(100 \%)$ and retention rates would give dropout rates. The rates were generated manually and given in the same Figure 1.

Figure 1 gives a fluctuating trend, especially, of national average dropout and retention rates for the years ranging from 2010 to 2017 with dropout rate being on the increase from 2012. This was inconsistent with the expectations concerning the effect of strategic plan implementation involving the stakeholders' awareness of vision and mission statements on internal efficiency because the introduction of strategic planning was geared to enhance efficiency. So what could be the problem?

The data provided by County Directors of Education of Kisumu and Uasin Gishu (2018 revealed that the two counties were having more or less similar repetition rates across from Form 1 to Form 4 in 2017 with Forms 3 and 4 recording the highest rates of repeaters as compared to the lower Forms indicating inefficient utilization of resources. This is indicated in Table 1 .

Table 1: County Grade Repetition Rates in 2017

\begin{tabular}{lcccc}
\hline County & \multicolumn{5}{c}{ Grade Repetition rates in \% } \\
\cline { 2 - 5 } & F1 & F2 & F3 & F4 \\
\hline Kisumu & 0.30 & 0.78 & 2.02 & 2.24 \\
Uasin Gishu & 0.53 & 0.83 & 1.82 & 2.4 \\
\hline
\end{tabular}

Source: Ministry of Education 2018

Repetition rates from Table 1 indicate that in both counties the repetition rates were still evident, despite being outlawed, ranging from the lowest rate of $0.30 \%$ to the highest $2.4 \%$ across the grades. These rates when compared with the rates of the rest of other counties, were found to be the highest. The rates were not insignificant in terms of cost. According to West (2012), estimated cost to society of retaining in the same grade $2.3 \%$ of the total population in the US is higher than $\$ 12$ billion per year. In addition, the two counties registered considerably high dropout rates as well as low retention rates in spite of Free Secondary Education (MoEST, 2012, 2014; Okungu, Orwa \& Mungatu, 2014) and evidence that they were implementing strategic planning process by having vision and mission statements printed on gates of all the schools and everywhere in the compound. Inefficiency of an educational system is a waste to the system. The fact that a student repeats a grade and spends five (5) years instead of four (4) student years or drops out implies an extra cost to the government and other stakeholders (Deribe, Endale \& AlShebir, 2015). 


\section{State of the Art Review}

Strategic plan has been confirmed to be a vital tool, which an institution can use to achieve targeted desires within a short period based on the analysis of both internal and external factors. It is a tool indispensable for the success of any educational programme (Chukwumah et al., 2015). Khan, et al. (2014) argue that Strategic Planning does not only specify the organization's vision, mission, core values and objectives but also allocates resources to achieve them. The vision and mission are among the school fundamental statements, which explicitly define the institution's destiny, and therefore every stakeholder should be aware of them. This will enable them have the same focus in their action hence utilization of the resources; however it was not clear whether the key stakeholders were aware of these statements.

According to Sang, Kindiki, Sang, Rotich and Kipruto (2015), clarity of school vision and mission statements; communication of the same to stakeholders; and ownership of the whole process by both the implementers and managers of the institutions, are strategic direction. The literature concludes that these factors lead to effective implementation of strategic plans. The reason is that strategic direction motivates stakeholders making them display their awareness of the statements in the process of strategic plan implementation. However, the literature fails to highlight whether the awareness of the stakeholders has effect on grade promotion and retention rates hence internal efficiency.

A study by Abdulkareem et al (2014) on Nigerian Universities contends that strategic plan implementation is meant to improve and achieve internal efficiency in the universities, especially when guided by stakeholders' awareness of vision and mission statements. However, what was unknown was whether the stakeholders' awareness of vision and mission statements would equally improve and achieve internal efficiency of public secondary schools in Kisumu and Uasin Gishu Counties.

Chukwumah and Ezeugbor (2015) argue that strategic planning is an indispensable tool for success of any educational programme but the effective implementation of strategic plan that would cause a shift from quantity to quality and the achievement of system-wide transformation as desirable goals was the thrust. Such implementation must be anchored on the stakeholders' awareness of vision and mission statements. This presented the current study with a viable area of interest to be explored -What exactly was the effect of stakeholders' awareness of vision and mission statements on internal efficiency in public secondary schools?

\section{Statement of the Problem}

A number of students access secondary education but did not graduate at the stipulated period. For instance, some of the students who enrolled in secondary schools in both Kisumu and Uasin Gishu Counties repeated grades while others dropped out yet there was glaring evidence that schools were implementing strategic plans. The implication was that the importance of education and training in sustainable development, which is provided for in the Constitution of Kenya (2010) that every child has a right to free and compulsory basic education and access to affordable tertiary education, training and skills development would not be realized. Failure to address strategic plan implementation through the stakeholders' awareness of vision and mission statements meant resources of public secondary schools would continue to be dilapidated leading to internal inefficiency in terms of repetition and dropout rates.

\section{Objectives and Hypotheses}

The study sought to achieve the following objectives:

i) To establish the effect of stakeholders' awareness of vision and mission statements on grade promotion rate in public secondary schools in Kisumu and Uasin Gishu Counties, Kenya.

ii) To investigate the effect of stakeholders' awareness of vision and mission statements on retention rate in public secondary schools in Kisumu and Uasin Gishu Counties, Kenya.

\section{Research Design and Methodology \\ 5.1 Research Design}

The study adopted convergent parallel mixed methods design, which is one of the six variants of mixed methods of research designs (Creswell, 2014). It mixes the results (triangulation) for supportive or non- supportive findings (Creswell, 2014) by merging the two databases in side-by-side comparison during overall interpretation as depicted in figure 2. 


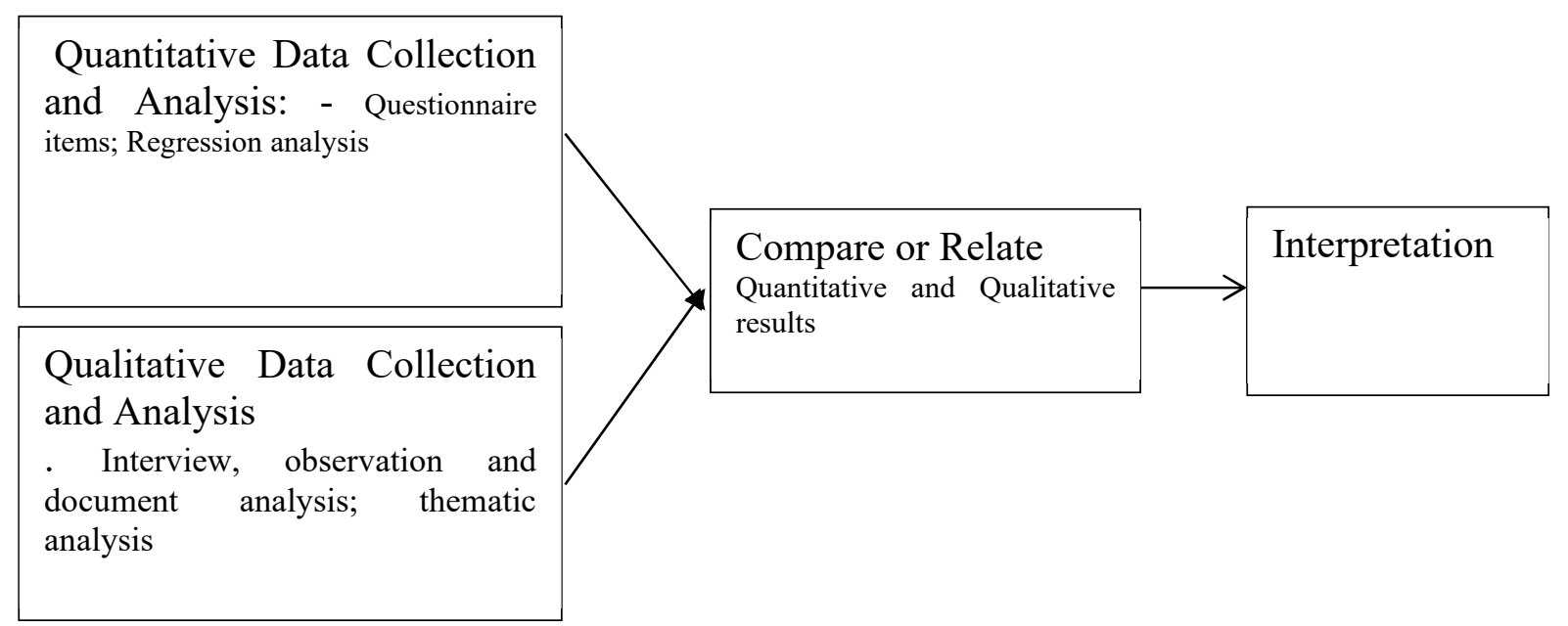

\section{Figure 2: The convergent parallel design model}

Source: (Creswell, 2014)

This design was chosen for the current study because of inconsistent results of the previous studies on the relationship between strategic planning and organizational performance which had been too general and not specific on the aspect of performance; and which used only one method. The target population was 2226 consisting of 371 Principals (221 from Kisumu and 150 from Uasin Gishu Counties); 1484 class teachers (884 and 600 from Kisumu and Uasin Gishu Counties respectively) and 371 PA chairpersons (221 and 150 from Kisumu and Uasin Gishu Counties respectively).

\subsection{Population and Sample}

The sample size for quantitative data was 342 respondents ( $15.4 \%$ of target population) consisting of 57 principals, 228 teachers and 57 PA chairpersons. Purposive sampling was used to select the principals and PA chairpersons while teachers were selected using simple random sampling. The sample size for qualitative data was 54(15.4\% of sample size for quantitative data) made up of 9 principals, 36 teachers and 9 PA chairpersons. All these respondents were purposively sampled.

\subsection{Data Analysis}

The quantitative data generated through questionnaires were edited and keyed in to a computer spreadsheet. Statistical Package for Social Sciences (SPSS) assisted to generate descriptive statistics such as percentage and frequency distribution were used. In addition, inferential statistics such as simple and stepwise multiple regressions were used to analyze the quantitative data. Qualitative data was analyzed with the guidance of grounded theory under themes consistent with the research objectives. The quantitative and qualitative data sets were triangulated to elicit trends and patterns to facilitate drawing plausible conclusions and suggestions for further research.

\section{Results and Discussion}

\subsection{Vision and Mission Statements Awareness and Internal Efficiency}

The first objective of the study was to establish the effect of awareness of school vision and mission statements by the stakeholders on internal efficiency in public secondary schools in Kisumu and Uasin Gishu Counties, Kenya. In this objective, the study focused on awareness of the vision and mission statements by the principals, teachers, PA chairpersons, students and parents, the effect of this awareness on retention and grade promotion rates.

\subsection{Stakeholders' Awareness of Vision and Mission Statements}

Stakeholders' awareness of vision and mission statements in the context of this study refers to having knowledge of the vision and mission statements by the members of the school community for instance, principal, teachers, PA chairperson, parents and students. The principals, teachers and PA chairpersons were requested to indicate whether the stakeholders were aware of the vision and mission statements.

(i) Principals' View on Stakeholders' awareness of Vision and Mission Statements

Principals' view stakeholders' awareness of vision and mission statements. The principals were requested to indicate whether the stakeholders were aware of the vision and mission statements. Their responses are summarized in Table 2. 
Table 2: Principals' response on stakeholders' awareness of Vision and Mission

\begin{tabular}{|c|c|c|c|c|c|c|c|c|c|c|}
\hline \multirow[b]{2}{*}{ Response } & \multicolumn{2}{|c|}{ Principal } & \multicolumn{2}{|c|}{ Teachers } & \multicolumn{2}{|c|}{ PA Chairperson } & \multicolumn{2}{|c|}{ Students } & \multicolumn{2}{|c|}{ Parents } \\
\hline & $\mathrm{N}$ & $\%$ & $\mathrm{~N}$ & $\%$ & $\mathrm{~N}$ & $\%$ & $\mathrm{~N}$ & $\%$ & $\mathrm{~N}$ & $\%$ \\
\hline Aware & 57 & 100 & 57 & 100 & 55 & 96.5 & 54 & 94.7 & 32 & 56.1 \\
\hline Not aware & 0 & 0 & 0 & 0 & 2 & 3.5 & 3 & 5.3 & 25 & 43.9 \\
\hline Total & 57 & 100 & 57 & 100 & 57 & 100 & 57 & 100 & 57 & 100 \\
\hline
\end{tabular}

From Table 2, all the principals confirmed that principals and teachers were aware of the vision and mission statements while $96.5 \%$ and $94.7 \%$ indicated PA chairpersons and students respectively were aware of the vision and mission statements. Further, $56.1 \%$ of the principals concurred that parents were aware of the vision and mission statements. The finding reveals that the principals as vision carriers and executives of the schools led, supported, followed up and lived the results of strategic planning process by being aware of the vision and mission statements. This concurs with the finding of Kevogo et al. (2015) that top managers must show commitment. By indicating, that the teachers, PA chairpersons, students and then parents followed such dedication and commitment reveals that the principals were conscious and keen about successful implementation of strategic plans and hence they gave strategic direction to these implementers to have the same focus.

(ii) Teachers' View on Stakeholders' awareness of Vision and Mission

Teachers view on the stakeholders' awareness of vision and mission statements is important because it is going to validate the view of the principals on the same. This is because teachers interact more with all the stakeholders of the school. The teachers were therefore requested to indicate whether the stakeholders were aware or not of the vision and mission statements. Their responses are as shown in Table 3.

Table 3: Teachers' response on stakeholders' awareness of vision and mission

\begin{tabular}{|c|c|c|c|c|c|c|c|c|c|c|}
\hline \multirow[b]{2}{*}{ Response } & \multicolumn{2}{|c|}{ Principal } & \multicolumn{2}{|c|}{ Teachers } & \multicolumn{2}{|c|}{ PA Chairperson } & \multicolumn{2}{|c|}{ Students } & \multicolumn{2}{|c|}{ Parents } \\
\hline & $\mathrm{N}$ & $\%$ & $\mathrm{~N}$ & $\%$ & $\mathrm{~N}$ & $\%$ & $\mathrm{~N}$ & $\%$ & $\mathrm{~N}$ & $\%$ \\
\hline Aware & 228 & 100 & 224 & 98.2 & 225 & 98.7 & 214 & 93.9 & 155 & 68 \\
\hline Not aware & & & 4 & 1.8 & 3 & 1.3 & 14 & 6.1 & 73 & 32 \\
\hline Total & 228 & 100 & 228 & 100 & 228 & 100 & 228 & 100 & 228 & 100 \\
\hline
\end{tabular}

From Table 3, all the teachers agreed that principals were aware of the vision and mission statements. Almost the same number of teachers, $98.7 \%$ and $98.2 \%$, indicated the awareness of the statements by PA chairpersons and teachers respectively. The awareness by students was confirmed by $93.9 \%$ of the teachers while more than two thirds of the teachers $(68 \%)$ confirmed that parents were aware of the statements.

The finding shows the teachers concurred with the principals that as vision carriers the principals were all aware of vision and mission statements. It implies that the teachers were confident of the strategic direction given to them by the principals. The finding also implies that most of the teachers, PA chairpersons, students and majority of parents were also committed to the strategic direction given to them for successful implementation of school strategic plan.

(iii) PA chairpersons' View on Stakeholders' awareness of Vision and Mission

PA chairpersons' view on stakeholders' awareness of vision and mission statements is significant to this study because it would ensure incorporation of different voices of stakeholders into the study. This is because strategic planning and implementation in learning institutions involves many important stakeholders and PA chairpersons such stakeholders in that they both represent parents and are part of the executives of school Boards. The PA chairpersons were therefore requested to indicate whether the stakeholders were aware of the vision and mission statements. Their responses are as shown in Table 4.

Table 4: PA chairpersons' response on stakeholders' awareness of Vision and Mission

\begin{tabular}{|c|c|c|c|c|c|c|c|c|c|c|}
\hline \multirow[b]{2}{*}{ Response } & \multicolumn{2}{|c|}{ Principal } & \multicolumn{2}{|c|}{ Teachers } & \multicolumn{2}{|c|}{ PA Chairperson } & \multicolumn{2}{|c|}{ Students } & \multicolumn{2}{|c|}{ Parents } \\
\hline & $\mathrm{N}$ & $\%$ & $\mathrm{~N}$ & $\%$ & $\mathrm{~N}$ & $\%$ & $\mathrm{~N}$ & $\%$ & $\mathrm{~N}$ & $\%$ \\
\hline Aware & 57 & 100 & 57 & 100 & 55 & 96.5 & 54 & 94.7 & 44 & 77.2 \\
\hline Not aware & 0 & 0 & 0 & 0 & 2 & 3.5 & 3 & 5.3 & 13 & 22.8 \\
\hline Total & 57 & 100 & 57 & 100 & 57 & 100 & 57 & 100 & 57 & 100 \\
\hline
\end{tabular}

$\mathbf{N}=\mathbf{5 7} \quad$ Source: PA chairpersons' questionnaire

From Table 4, all the PA chairpersons agreed that principals and teachers were aware of the vision and mission statements. Majority of the PA chairpersons confirmed the awareness of the statements by PA chairpersons and students at $96.4 \%$ and $94.7 \%$ respectively. Further, more than three quarters of the PA chairpersons (77.2) indicated that parents were aware of the statements. The finding implies all inclusivity of strategic plan implementation in the sampled schools in the study locale. This is because the PA chairpersons could not give similar response to the ones given by the principals and teachers as can be seen in Tables 2 and 3 if they were not involved in the process.

Qualitative finding corroborates the quantitative finding on awareness of vision and mission statements by 
establishing that the process of formulating fundamental statements had aspect of inclusivity and hence creation of awareness among the stakeholders.

\subsection{Stakeholders' level of Vision and Mission Awareness}

All the stakeholders' level of vision and mission awareness refers to the overall assessment of all the stakeholders' awareness of vision and mission statements. This information is considered important because it was to help in running the regression analysis to establish the effect of stakeholders' awareness of vision and mission statements on internal efficiency. The principals, teachers and PA chairpersons were as such requested to give their overall opinion on the level of the stakeholders' awareness of vision and mission based on their earlier views in Tables 2 , 3 and 4. The responses were as shown in Table 5.

Table 5: Respondents' Responses on level of awareness of all the stakeholders

\begin{tabular}{lcccccc}
\hline \multirow{2}{*}{ Awareness } & \multicolumn{2}{c}{ Principal } & \multicolumn{2}{c}{ Teachers } & \multicolumn{2}{c}{ PA Chairperson } \\
\cline { 2 - 7 } & $\mathbf{N}_{\mathbf{1}}$ & $\mathbf{0}$ & $\mathbf{N}_{\mathbf{2}}$ & $\mathbf{\%}$ & $\mathbf{N}_{\mathbf{3}}$ & $\mathbf{\%}$ \\
\hline No awareness at all & 0 & 0 & & & 1 & 1.8 \\
Less awareness & 7 & 12.3 & 52 & 22.8 & 8 & 14 \\
Moderate awareness & 36 & 63.2 & 134 & 58.8 & 35 & 61.4 \\
Great awareness & 12 & 21.0 & 42 & 18.4 & 13 & 22.8 \\
Very great awareness & 2 & 3.5 & & & 0 & 0 \\
\hline Total & $\mathbf{5 7}$ & $\mathbf{1 0 0}$ & $\mathbf{2 2 8}$ & $\mathbf{1 0 0}$ & $\mathbf{5 7}$ & $\mathbf{1 0 0}$
\end{tabular}

Source: Principals' questionnaire, Teachers' questionnaire and

PA Chairpersons' questionnaire

$$
\begin{aligned}
& \mathrm{N}_{1}=57 \\
& \mathrm{~N}_{2}=228 \\
& \mathrm{~N}_{3}=57
\end{aligned}
$$

From the Table 5, majority of the respondents (63.2\% of the principals, $58.8 \%$ of teachers and $61.4 \%$ of PA chairpersons) concurred that vision and mission awareness of the stakeholders was moderate. The principals and PA chairpersons almost concurred as $21.8 \%$ and $22.8 \%$ respectively felt that the awareness was great while only $18.4 \%$ of teachers indicated the same level of awareness. Less awareness was indicated by $22.8 \%$ of teachers, $14 \%$ of PA chairpersons and $12.3 \%$ of principals. Finally, no awareness at all and very great awareness were preferred in the same way in that $3.5 \%$ of the PA chairpersons, $0.4 \%$ of the teachers and $0 \%$ of the principals indicated no awareness at all while $3.5 \%$ of the principals, $0.4 \%$ of the teachers and $0 \%$ of the PA chairpersons indicated very great awareness. This finding implies that further sensitization of stakeholders on awareness of vision and mission statements was still necessary since moderate level of awareness could mean moderate strategic implementation of strategic plan.

\subsection{Retention and Grade Promotion Rates}

Retention rate refers to the proportion of students who enrolled in a given grade, remained and progressed in school until they completed their secondary school life in Form 4. On the other hand, Grade Promotion Rate refers to the proportion of students from a cohort enrolled in a given grade at a given school year who progressed to the next grade in the following year. These are two important indicators of internal efficiency. Information about them would help to assess the effect of strategic plan implantation on internal efficiency that this study was all about.

\section{(a) Grade Promotion Rates}

Grade Promotion Rates in this study refers to the average rate of the progression of students from one grade to another in the last five years by the time of data collection. This information is important since it was going to help determine the effect of strategic plan implementation on grade promotion rate and hence internal efficiency. The principals, teachers and PA chairpersons were therefore requested to indicate their opinion concerning the status of grade promotion rates in their schools from 2014. Their responses are as summarized in Figure 3. 


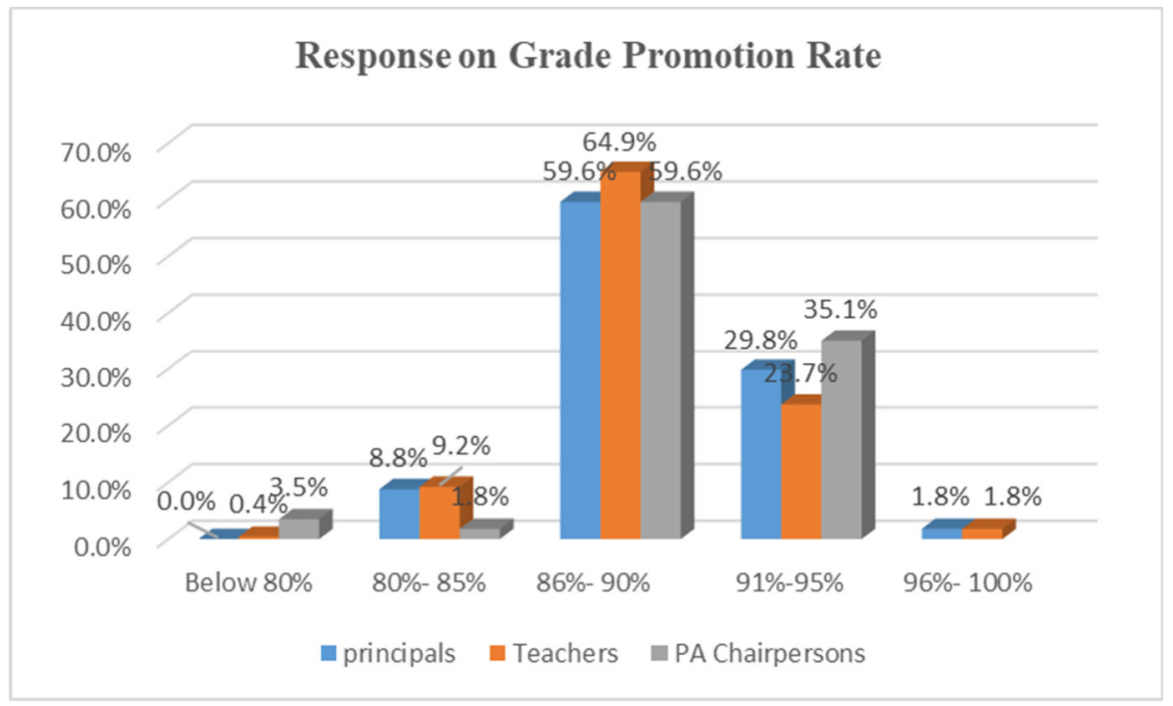

Figure 3: The status of grade promotion rates

Source: Principals' questionnaire, Teachers' questionnaire and PA Chairpersons' questionnaire

Figure 3 , shows that majority of the respondents $(64.9 \%$ of teachers and $59.6 \%$ of both principals and PA chairpersons), indicated that grade promotion rate was ranging between $86 \%$ and $90 \%$ while $35.1 \%$ of PA chairpersons, $29.8 \%$ of principals and $23.7 \%$ of teachers indicated grade promotion rate was between the range of $91 \%$ and $95 \%$ in public secondary schools in the study locale. There was yet a category of respondents $(9.2 \%$ of teachers, $7.0 \%$ of principals and $1.8 \%$ of PA chairpersons) who indicated that grade promotion rate was between $85 \%$ and $90 \%$ while another group of respondents (3.5\% of principals and $1.8 \%$ of teachers) indicated that grade promotion rates was within the range between $96 \%$ and $100 \%$. Further, $3.5 \%$ of PA chairpersons and $0.4 \%$ of teachers indicated that the rate was below $80 \%$ in public secondary schools in Kisumu and Uasin Gishu Counties. This finding reveals majority of the respondents concurred that grade promotion rate was between $86 \%$ and $100 \%$ which is in agreement with the finding of MoEST (2014). This could only be possible by fixing some factors during the five years. The finding concurs with Itegi (2016) that successful schools examine their missions and visions, assess their current state, set new goals, determine action plans to achieve their set goals and measure progress towards goals. For that reason, the effect of stakeholders' awareness of vision and mission statements on internal efficiency (grade promotion rate and retention rate) was further investigated using regression analysis.

\section{(b) Retention Rates}

Retention Rates in this study refers to the average rate of the remaining of students in school throughout their secondary school life cycle in the last five years by the time of data collection. This information is important since it was going to help determine the effect of strategic plan implementation on retention rate and hence internal efficiency. The principals, teachers and PA chairpersons were therefore requested to indicate their opinion concerning the status of retention rates in their schools from 2014. Their responses are depicted in Figure 4.

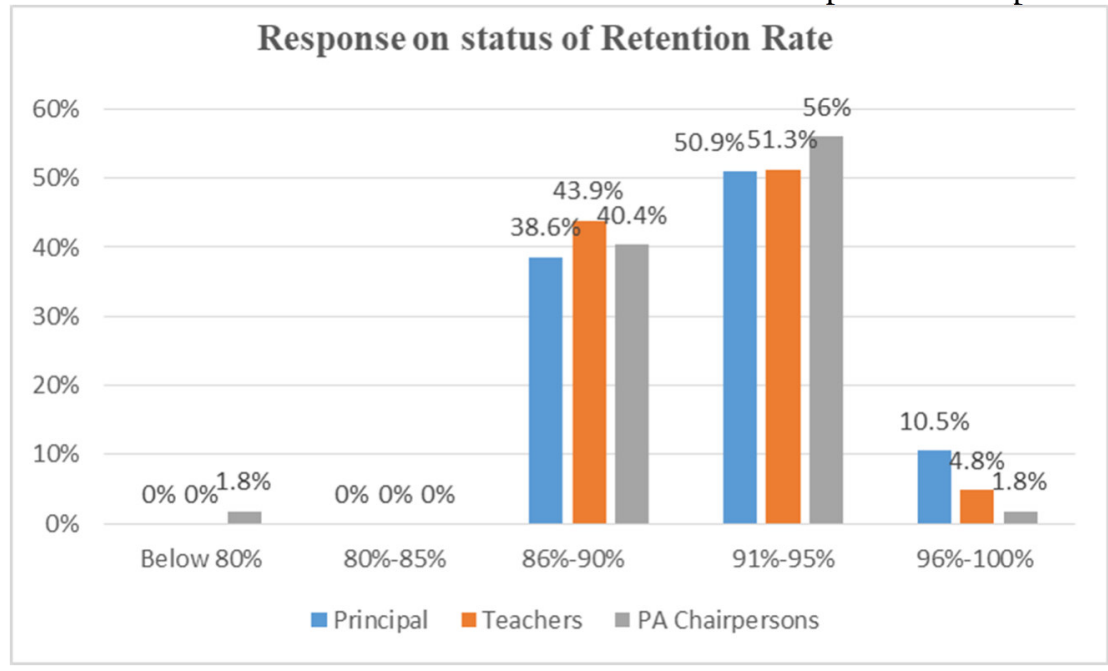

Figure 4: The status of retention rate

Source: Principals' questionnaire, Teachers' questionnaire and PA Chairpersons' questionnaire 
From Figure 4, majority of the respondents (61.4\% of principals, $56.1 \%$ of teachers and $57.8 \%$ of PA chairpersons) indicated that retention rate was at between $91 \%$ and $95 \%$. On the other hand, $43.9 \%$ of teachers, $40.4 \%$ of PA chairpersons and $38.6 \%$ of principals agreed that the retention rate was between $86 \%$ and $90 \%$. Further, $10.5 \%, 4.8 \%$ and $1.8 \%$ of principals, teacher and PA chairpersons indicated $96 \%-100 \%$ of retention rate while only $1.8 \%$ of PA chairpersons indicated that retention rate was below $80 \%$ in public secondary schools in the study locale. This finding is corroborated by analysis of data obtained from document analysis on retention in the sampled schools. The analysis reveals that the average retention rate was $95.6 \%$

There is convergence between quantitative and qualitative findings that retention rate in the public secondary schools was higher as compared to the national retention rate of $76.4 \%$ in 2014 (MoEST,2014). It is for this reason that this study went further to examine how strategic plan implementation helped in fixing these factors to improve internal efficiency.

\subsection{Effect of Vision and Mission Statements Awareness on Internal Efficiency}

Vision and mission statement awareness was considered in this study to mean having the knowledge of vision and mission statements. This variable was significant because it could have an influence on internal efficiency (grade promotion rates and retention rates) in public secondary schools in the study locale. In this regard, a simple linear regression analysis was conducted involving the first predictor of independent variable (awareness of vision and mission statements) and dependent variables (grade promotion rates and retention rates). The analysis was done in SPSS. The results are presented in Table 6.

Table 6: Statistical measurements of the effect of stakeholders' awareness of vision and mission statements on internal efficiency

Dependent variable: Participation

$\begin{array}{lcc}\text { Regression } & \text { Model 1 } & \text { Model 2 } \\ \text { Statistics } & \text { Grade Promotion Rates } & \text { Retention Rates }\end{array}$

$\begin{array}{lll}\mathrm{R} & .727 \quad .369\end{array}$

Predictor: Awareness $\mathrm{R}$ - squared $\left(\mathrm{R}^{2}\right) \quad .529 \quad .136$

$\begin{array}{llll}\text { Of vision and mission } \quad \text { Adjusted R-squared }\left(\mathrm{R}^{2} \text { adj) }\right. & .529 & .134\end{array}$

Statements by $\quad$ Beta $(\beta) \quad .682 \quad .360$

$\begin{array}{llll}\text { Stakeholders } & \text { Standard error of Est }(\varepsilon) \quad .43625 \quad .61362\end{array}$

$\begin{array}{lll}\text { Constant } & 1.151 & 2.484\end{array}$

Durbin - Watson $\quad 1.807 \quad 1.711$

Model 1 in Table 6 illustrates data of a simple correlation between the predictor/independent variable component (Awareness of vision and Mission statements by stakeholders) and the first measure of the dependent variable (Grade Promotion Rate) of students in public secondary schools in Kisumu and Uashin Gishu counties, Kenya. The Pearson's $\mathrm{R}=.727$ shows that there is a strong positive linear relationship between awareness of vision and mission statements by stakeholders and students' Grade Promotion Rate in public secondary schools in Kisumu and Uashin Gishu counties, Kenya. The R-squared $\left(\mathrm{R}^{2}\right)$ computed yielded a value of .529, suggesting that stakeholder's awareness of vision and mission statement explained 52.9 percent of the variations in students' grade promotion rate in public secondary school in the study locale. The adjusted R-squared $\left(\mathrm{R}^{2}\right)$ also illustrates that awareness of the vision, mission statements explained 52.7 percent of the variations in students Grade Promotion rate, and it is lower than $\mathrm{R}^{2}$ predicted. This is an expected finding because the $\mathrm{R}^{2}$ adjusted is usually lower than $\mathrm{R}^{2}$.

The Beta weight (.682) value predicts that one unit change in the increase in the level of stakeholders' awareness of vision and mission statements is expected to cause .682 increase in Grade Promotion rate in public secondary schools in Kisumu and Uashin Gishu counties, Kenya.

The constant value suggests that the predicted value of grade promotion rate in public secondary schools is 1.151 if the value of the awareness of vision and mission statements is zero. The standard error of estimate $(\varepsilon)$ was found to be .43625 , suggesting that there were other factors of magnitude .43625 that influence the students' grade promotion rate but not observed or taken into account. These could be among other factors such as intervening variables. The Durbin - Watson statistics is a number that tests for auto correlation in the residuals from statistical regression analysis. The Durbin - Watson statistics is always between zero (0) and (4). A value approaching 2, as obtained in the model 1 means that there is no auto correlation in the sample values. Values approaching 4 illustrate auto correlation and values approaching 0 indicate positive auto correlation.

Model 2 presented in Table 6 contains data on the effect of awareness of vision and mission statements (predictor) on the retention of students in public secondary schools in Kisumu and Uashin Gishu counties, Kenya. 
The Pearson's $\mathrm{R}=.369$ indicates that there was a positive relationship between the awareness of school vision and mission statements and retention rate in public secondary schools in Kisumu and Uashin counties, Kenya. The R - squared $\left(\mathrm{R}^{2}\right)$ computed yielded a value of .136 suggesting that awareness of the school vision and mission statements explained $13.6 \%$ of the variation in retention in public secondary schools in the study locale with $86.4 \%$ being explained by other factors not included in the model. The adjusted $\left(\mathrm{R}^{2}\right)=.134$ confirmed that awareness of school vision and mission statements explained over $13 \%$ of the variation in retention rate. The Beta weight $(\beta=.360)$ predicts that one unit change in the stakeholders' awareness of school vision and mission statements is expected to cause .360 increase in the retention in public secondary school in the study locale.

The constant value suggests that the predicted value of retention rate is 2.484 if the value of stakeholders' awareness of vision and mission statements is zero. The standard error of the estimate $(\varepsilon)$ was found to be .61362 , suggesting that there were other factors not observed in the model but which had some influence on the retention of students. The Durbin - Watson value of 1.711 in model 2 indicated that there was no auto - correlation in sample data.

The finding reveals that there is a positive correlation between stakeholders' awareness of vision and mission statements and grade promotion rate as well as retention rate. However, the correlation between the awareness and grade promotion rate was higher at .727 than between awareness and retention rate at .369 . This implies that the influence of stakeholders' awareness of vision and mission statements was greater on grade promotion rate than on retention rate as confirmed by the simple linear regression coefficients $\left(\mathrm{R}^{2}=.527\right.$ and .136 respectively). This means that Stakeholders' awareness of vision and mission statements can influence $52.7 \%$ and $13.6 \%$ of grade promotion rate and retention rate respectively.

The principals, teachers and PA chairpersons who were interviewed reported that the awareness of the statements had influenced greatly, both grade promotion rate and retention rate. This was because the stakeholders' awareness of vision and mission statements made each of them play their roles with commitment leading to better performance of students academically hence grade promotion rate, which ultimately made students remain in school.

The convergence between quantitative and qualitative findings was that the results established influence of stakeholders' awareness of vision and mission statements on grade promotion rate and retention rate of students, hence internal efficiency. The influence is greater on grade promotion rate than on retention rate. The findings of the current study have gone further to fill the gap left by (Sang et al 2015, Chemei et, al. 2014 and Itegi 2016) by establishing that the awareness of school vision and mission statements by stakeholders has influence promotion and retention rates.

\section{Conclusions and Recommendations}

The major thrust of the study conveyed in this paper was to highlight the issue concerning stakeholders' awareness of vision and mission statements and the effect of such awareness on internal efficiency in public secondary schools in the study locale. Based on the research findings and discussion of the findings in relation to the art of literature, it is concluded that just having the statements on the gate walls, noticeboards or in prints is not enough to create deeper understanding. A lot more needs to be done. The stakeholders' awareness was moderate and it was due to all-inclusivity during the formulation process of the statements. This awareness had higher influence on grade promotion rate than on retention rate. However, the influence was positive in both cases.

Because of the findings, summary and conclusions, the following recommendations are made. The Government of Kenya through the Ministry of Education and together with the stakeholders in various secondary schools should undertaking the following:

Regular and consistent sensitization of stakeholders on school vision and mission statements as schools ensure that their vision statement is regularly reviewed and appropriately stated to capture the scope in SMART terms and clearly stated such that the two statements are easily recognized.

\section{Declaration of Competing Interests}

We wish to declare that this paper has been developed purely from my postgraduate academic research thesis that was self-sponsored in its entirety. We also wish to declare that no personal business interests or affiliations to any school, company or organization that may claim party or will be affected/beneficial from the research findings of this paper.

\section{References}

Abdulkareem, Y.A; Akinubi, P.D., \& Oyenivan, S. (2014). Strategic plan implementation and internal efficiency in Nigerian universities. European Scientific Journal.Vol.8, No 3 ISSN: 1857-7882, ISSN 1857-7431.

Chemwei, B., Leboo, C., \& Koech, S. J. (2014). Factors that Impede the Implementation of Strategic Plans in Secondary Schools in Baringo District, Kenya. International Journal of Humanities and Social Science 4(5). Chukwumah. F.O., \& Ezeugbor, C.O. (2015). Problems of Implementation of Strategic Plans for Secondary 
Schools' Improvement in Anambra State. Academic Journals Vol (10)(10) pp.1384-1389.

Creswell, J. W. (2014). Research Design: Qualitative, Quantitative and Mixed Methods Approaches (4th Ed.). Thousand Oaks, CA: Sage.

Itegi, F. M. (2016). Financing Secondary Education in Kenya: Exploring Strategic Management Approach for Improving Quality of Education. Universal Journal of Educational Research 4(5):949-955, 2016 DOL: 10.13189/ujer.2016.040503

Khamati, J. M., \& Nyongesa, J.W. (2013).Factors influencing Implementation of Free Secondary Education in Mumias District, Kenya. Journal of Social Science for Policy Implications1 (1)32-47.

Khan, J. W. M \& Khalique, M. (2014). A Holistic Review of Empirical Studies of Strategic Planning and Future Research Avenues. International Journal of Academic Research in Economics and Management Science Vol. 3, No. 6 ISSN: 2226-362.

Kevogo, A. A., \& Waiganjo, E. (2015). Factors influencing Implementation of Strategic Plans in Public Secondary Schools in Kenya: A survey of Public Secondary Schools in Thika West Sub-County. The Strategic Business \& Change Journal of Management Vol 2, Iss. 2(117), pp 1899-1914.

Kiprop.C.J, Bomett, E.J, \& Michael, J.J. (2015). Strategic Planning in Public secondary Schools in Kenya: Challenges and mitigations. Intention Journal of Advanced Research in Education and Technology (JARET) 2(4).

Kisumu County Director of Education Report on Enrolment (2018).

Ministry of Education. (2018). Report on Enrolment. Government Printer, Nairobi.

MoEST. (2014). Basic educational Statistical Booklet. Nairobi. Government Printers, Kenya.

MoEST. (2012). Management of primary and secondary school curriculum. Nairobi: Ministry of education.

MoEST. (2007). Management of Primary and Secondary Education Curriculum. Nairobi: Unpublished Education Circular.

Okungu, J.O. Orwa, G. \& Mungatu, J. (2014). The Retention Rates of Students in Public Secondary Schools using The Cox Propositional Hazard Model: A case of Kisumu County, ISTE 4(10)2225-6522.

Republic of Kenya. (2010). The Constitution of Kenya. Nairobi: Government Printer.

Republic of Kenya. (2012). Sessional Paper No. 10 of 2012 on Vision 2030. Nairobi. Government Press.

Republic of Kenya. (2013). Kisumu County integrated development plan 2013 - 2017. Nairobi. Government Printers.

Republic of Kenya. (2013). Uasin Gishu County integrated development plan 2013-2017 Government Printers.

Republic of Kenya. (2014). Education for all. The 2015 National Review. Government Press. Nairobi.

Republic of Kenya. (2013). Ministry of Education, Science and Technology, Strategic Plan 2013-2017, Kenya vision 2030. Government Printing Press .NBI.

Republic of Kenya. (2015). Facts and figures. Kenya National Bureau of Statistics. Government printers. Nairobi. Republic of Kenya. (2016). 2017/18- 2019/20 Education Sector Report. Government Printers. Nairobi.

Sang, F.K., Kindiki, J.N., Sang, J.K., Rotich, G.J., \& Kipruto, K. (2015). Availability and The Level of Implementation of Strategic Plans in Secondary Schools in Nandi County, Kenya. Sage Open, DOC: $10.1177 / 2158244015577417$.

Steyn; H. \& Wolhuter, C. (2010). Creative sustainable learning environment of schools by means of strategic planning. The Experience of Engagement by Comparative Education Teams at University, South African Journal of Higher Education 24(3); 56- 70.

Uasin Gishu County Director of Education Report on Enrolment (2018).

UNESCO. (2015). Education 2030. Incheon Declaration and Framework for Action Towards inclusive and equitable quality education and lifelong learning For all UNESCO.

UNESCO. (2000). The Dakar Framework for Action Education for all: Meeting our Collective commitments. PARIS, UNESCO.

West, M. R. (2012). "Is Retaining Students in the Early Grades Self-Defeating?" CCF Brief \# 49, Center on Children and Families at Brookings. 